\title{
Genetic polymorphism and chronic obstructive pulmonary disease
}

\author{
This article was published in the following Dove Press journal: \\ International Journal of COPD \\ 10 May 2017 \\ Number of times this article has been viewed
}

\section{Cunhua Yuan' \\ De Chang ${ }^{2}$ \\ Guangming $\mathrm{Lu}^{3}$ \\ Xiaowei Deng'}

'Health Medical Center, ${ }^{2}$ Department of Respiratory Medicine, General Hospital of Chinese People's Armed Police Forces, ${ }^{3}$ Institute of Health Management, Chinese PLA General Hospital, Beijing, People's Republic of China
Correspondence: De Chang Department of Respiratory Medicine, General Hospital of Chinese People's Armed Police Forces, 69 Yongding Road, Haidian, Beijing, 100039, People's Republic of China

Email changde550।@foxmail.com

Guangming Lu Institute of Health Management, Chinese PLA General Hospital, 83 FuXing Road, Haidian, Beijing, 100039, People's

Republic of China

Emailgmlu30I@I63.com

\begin{abstract}
Chronic obstructive pulmonary disease (COPD) is a common chronic disease, and its morbidity and mortality are increasing. There are many studies that have tried to explain the pathogenesis of COPD from genetic susceptibility, to identify the susceptibility of COPD factors, which play a role in early prevention, early detection and the early treatment. However, it is well known that COPD is an inflammatory disease characterized by incomplete reversible airflow limitation in which genes interact with the environment. In recent years, many studies have proved gene polymorphisms and COPD correlation. However, there is less research on the relationship between COPD and genome-wide association study (GWAS), epigenetics and apoptosis. In this paper, we summarized the correlation between gene level and COPD from the following four aspects: the GWAS, the gene polymorphism, the epigenetics and the apoptosis, and the relationship between COPD and gene is summarized comprehensively.
\end{abstract}

Keywords: chronic obstructive pulmonary disease, COPD, genetic polymorphism, genomewide association study

\section{Introduction}

Chronic obstructive pulmonary disease (COPD) is a disease characterized by longterm poor airflow from the lungs. Early symptoms are mild and often do not warrant clinical intervention; therefore, patients actively seek medical treatment only when airway limitation is more severe and activity endurance is significantly decreased. At that time, stage III or IV COPD would have developed, along with cor pulmonale, heart failure or respiratory failure. All of these factors thereby reduce the quality of life of patients. Furthermore, disability and mortality rates in patients with COPD are high. COPD is, therefore, associated with a high economic burden both on national and international levels. A history of smoking is considered to be the most important factor leading to COPD; however, life-long smokers have only $10 \%-20 \%$ lifetime incidence of COPD. Furthermore, a small proportion of nonsmokers also develop COPD, and a number of people diagnosed with airway limitation in childhood may also present with COPD later in life. These factors suggest a familial genetic component to the disease. Polymorphisms, caused by mutations in gene loci, may be associated with the pathogenesis of COPD, and multiple genes may contribute to the pathogenesis of COPD. In this review, the associations of a number of genes with COPD are discussed (Table 1).

\section{Genome-wide association analysis of emphysema genetic factors}

Genome-wide meta-analysis of emphysema by Boueiz A et al showed that multicohort genome-wide association study (GWAS) of emphysema distribution has identified 
Table I Genes involved in pathogenesis of COPD

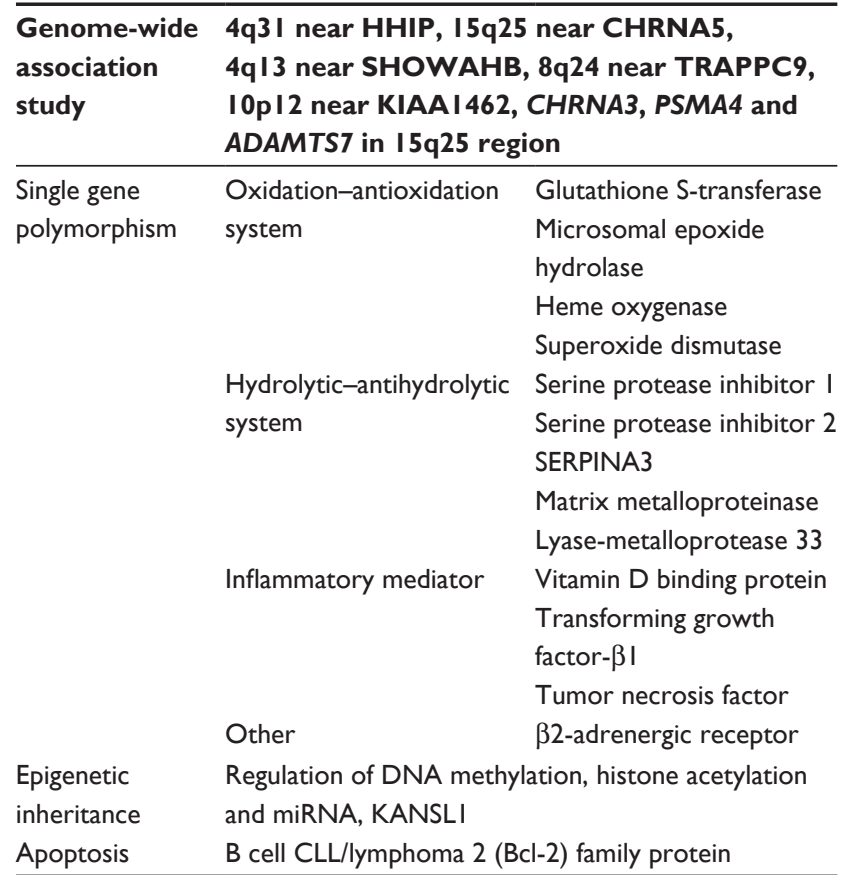

Abbreviations: COPD, chronic obstructive pulmonary disease; miRNA, microRNA; TRAPPC9, trafficking protein particle complex 9

five significant loci. ${ }^{1}$ It has been previously confirmed that $4 \mathrm{q} 31$ near hedgehog interacting protein (HHIP) and $15 \mathrm{q} 25$ near cholinergic receptor nicotinic alpha 5 subunit (CHRNA5) are associated with susceptibility to COPD driven by smoking behavior, whereas 4q13 near SHOWAHB, 8q24 near trafficking protein particle complex 9 (TRAPPC9) and 10p12 near KIAA1462 are newly identified genes, associated with susceptibility to COPD. Manichaikul et al found that rs10411619 near MAN2B in a Spanish population and rs7698250 near DHX15 and rs7221059 near MGAT5B in a Chinese population are significant in genome-wide analysis. ${ }^{2}$ Furthermore, the study also highlighted that the genes CHRNA3, PSMA4 and ADAMTS7 within chromosome $15 \mathrm{q} 25$ region may be associated with COPD2. Of these genes, the former has been reported to be associated with COPD, while the latter gene has not. PCDH9 is an adhesion molecule belonging to the cadherin family. In a GWAS of adults with decreased lung function with no history of asthma, two single-nucleotide polymorphisms (SNPs) of PCDH9, rs17077331 and rs 17077335, were associated with a decrease in forced expiratory volume in the first second $\left(\mathrm{FEV}_{1}\right)$ /forced vital capacity (FVC) in nonasthmatic patients. In the UK BiLEVE study done by Louise et al, 50,008 subjects were selected and six new genome-wide signals were found to be associated with $\mathrm{FEV}_{1}$, including four new loci (KANSL1, TSEN54, TET2 and RBM19/TBX5) and two previously reported loci (NPNT and HLA-DQB1/HLA-DQA2). ${ }^{3}$ These loci were also associated with COPD even in nonsmokers, and the study also found five new signals related to smoking, including a variant of NCAM1 (chromosome 11) and variants on chromosome 2 (TEX41 and PABPC1P2). In another study, a meta-analysis found that 43 signals were associated with one or more of $\mathrm{FEV}_{1}, \mathrm{FVC}$, or $\mathrm{FEV}_{1} / \mathrm{FVC}$ in the whole genome, 33 of which were new loci and 10 were statistically independent risk loci, and these loci explain the decline of lung function from the genetic aspects. ${ }^{4}$ In this study, the UK BiLEVE was used to study the individual variability and the 95 -variance risk score. However, none of these variants was found to be associated with acute exacerbation of COPD. In a large-scale, multicenter study by Peter et al, aiming to investigate the genetic and epidemiological characteristics of COPD, genome-wide association analysis showed that seven loci were significantly associated with COPD3. Two of the identified loci were polymorphisms rs379123 in MYO1D and rs9590614 in VMA8, both of which are associated with cell-to-cell signal transduction and cell migration. The other reported five loci from the study were HHIP, IREB2/ CHRNA3, CYP2A6/ADCK, TGFB2 and MMP12, and five of these seven loci are located in enhancer and DNase I hypersensitive regions of genes in lung fibroblasts or small airway epithelial cells. Indeed, GWAS of emphysema patients diagnosed with CT criteria shows that DLC1 and AGER are susceptibility genes for COPD4. The recent genome-wide association analyses show that 97 signals, enriched in development, elastic fibers and epigenetic regulation pathways, are related with COPD susceptibility. ${ }^{4}$

The possible genes associated with the pathogenesis of COPD will be discussed in the following sections.

\section{COPD and gene polymorphisms in the oxidative-antioxidative system Glutathione S-transferase}

Glutathione S-transferase (GST) is an enzyme that metabolizes various toxic substances. GST cytoplasmic enzymes are divided into eight categories: alpha (GSTA), mu (GSTM), pi (GSTP), theta (GSTT), sigma, zeta, kappa and chi. ${ }^{5}$ These enzymes show a high degree of polymorphisms and are closely associated with the occurrence and development of COPD. At present, the majority of studies have implicated mu1 (GSTM1), pi1 (GSTT1) and theta1 (GSTP1) with an increased risk of the development of COPD.

GSTM1 is located in the region 1p13.3, and GSTM1 homozygous deletion removes protein expression, thereby preventing the detoxification. GSTM1 has three loci, one 
of which is an invalid allele, and cannot be detected in homozygous cases. Harrison et al studied 111 lung cancer patients with emphysema and found that GSTM1 gene deletion is significantly higher than that in a healthy control group (odds ratio $[\mathrm{OR}]=1.36, P<0.05$ ). ${ }^{6}$ Shukla et al conducted a case-control study examining 204 COPD patients and 208 healthy controls and found that the frequency of the GSTM1 homozygous genotype in COPD patients is significantly higher than healthy controls $(\mathrm{OR}=2.58 ; 95 \%$ confidence interval $[\mathrm{CI}]=1.73-3.84 ; P=0.001){ }^{7}$

GSTT1 is located in chromosome $22 q 11.2$ region, and not expressed in the lungs. It is thought that GSTT1 protect the lungs by antagonizing systemic oxidative stress and alleviating inflammation within the lungs. Currently, it is fully understood whether absence of GSTT1 is directly implicated in COPD.

GSTP1 is strongly expressed in the alveoli, alveolar macrophages and bronchioles, and polymorphism in the position 105 results in mutations. A recent Japanese study showed that the GSTP1 105lle polymorphism is associated with airflow limitation, which causes a rapid decline in $\mathrm{FEV}_{1}$, as well as other lung function parameters. ${ }^{8}$ However, the studies by Yang L et al did not find an association between GSTP1 and COPD. ${ }^{9}$

\section{Microsomal epoxide hydrolase}

Microsomal epoxide hydrolase $(\mathrm{mEH})$ is a biotransformation enzyme that catalyzes the hydrolysis of various exogenous epoxides. ${ }^{10}$ It has been demonstrated previously that cigarette smoke contains a significant number of epoxides. Failure to remove epoxides through hydrolysis by $\mathrm{mEH}$ often results in several detrimental biochemical effects. Indeed, epoxides can combine with RNA, DNA and proteins in tissues to produce serious cytotoxic and genotoxic effects. $\mathrm{mEH}$ hydrolyzes and oxidizes the above-mentioned tissues and increases the secretion of proteases, and thus makes the trachea, bronchus and alveoli subject to varying degrees of damage, which result in airway obstruction and gradual development of COPD. Hassett et al demonstrated that mutations may be present at two loci, which leads to $\mathrm{mEH}$ having four possible alleles. ${ }^{11}$ Two mutation loci are located at exon 4 and exon 3 , and a T-to-C mutation occurs in the base of exon 3 resulting in an amino acid change of Tyr113 to His, thus reducing enzymatic activity by $50 \%$, and is therefore dubbed the slow allele. An A-to-C mutation occurs in the base of exon 4 to change the amino acid from His139 to Arg, thus increasing enzyme function by $25 \%$, and is, therefore correspondingly known as the fast allele. The polymorphisms of exon 3 and exon 4 are closely associated with mEPHX activity. Sandford et al found that the homozygous His113/His139 mEH haplotype is significantly associated with a rapid decline in lung function parameters $(\mathrm{OR}=4.9, P=0.04)$ in $\mathrm{COPD}$ patients with a family history. ${ }^{12}$ Further to these findings, Yim et al used restriction fragment length polymorphism polymerase chain reaction (PCR-RFLP) to carry out genotyping assays for mEPHX of 83 patients with COPD and 76 healthy smoking controls in South Korea. ${ }^{13}$ The authors compared MEPHX gene polymorphisms and frequencies between COPD patients and the healthy control group and found that the difference in the frequency of genotype polymorphisms was not statistically significant between mEPHX gene exons 3 and 4. Furthermore, the differences in genotype frequency were still not apparent after arbitrary combination of genotypes, suggesting that mEPHX gene polymorphisms may have no association with the development of COPD in South Korea. An et al reported that there was no association between EPHX1 and COPD in Caucasians and East Asians. ${ }^{14}$

\section{Heme oxygenase}

Heme oxygenase-1 (HO-1) is the main enzyme involved in heme catabolism and is primarily expressed in the lung, liver and heart, with its main role acting to prevent oxidative damage. The Wei's study, which induced HO-1 by infection of hemoglobin in rat model of emphysema caused by exposure to cigarette smoke, has demonstrated that $\mathrm{HO}-1$ has anti-inflammatory effects and can prevent smoke-induced emphysema from developing. ${ }^{15}$ In vivo study in mice has indicated that HO-1 is an important component participating in the balance of oxidative and antioxidative systems within the lung. (GT) n repeat microsatellite sequences in the $5^{\prime}$-end region of the human HO-1 gene may decrease the level of gene transcription under the effects of temperature and pressure. Longer microsatellite and GT repeats can protect lung tissue from damage of the active oxygen system. Therefore, a reduction in GT repeat sequences, caused by reduced transcription levels, may easily relate to the pathogenesis of COPD. Yamada et al conducted a study on the relationship between the (GT) n repeat number and the development of emphysema in two groups of 101 smokers with and without emphysema, and found that the (GT) n repeat polymorphism is divided into three categories: class $\mathrm{S}$ allele (repeat number $<25$ ), grade $\mathrm{M}$ allele (repeat number 25-29) and class $\mathrm{L}$ allele (repeat number $\geq 30$ ). ${ }^{16}$ Furthermore, the authors went on to show that grade $\mathrm{L}$ allele frequency and the proportion of class $\mathrm{L}$ allele $(\mathrm{L} / \mathrm{L}, \mathrm{L} / \mathrm{M}$ and $\mathrm{L} / \mathrm{S})$ in smokers with COPD were significantly higher than those in smokers 
without emphysema. A high number of (GT) n repetitive sequences are strongly associated with susceptibility to emphysema due to smoking. However, in a case-control study by He et al, the number of GT repeats of HO-1 gene in Caucasian smokers was not associated with a decline in lung function. Therefore, its association with COPD remains to be confirmed by further studies. ${ }^{8}$

\section{Superoxide dismutase}

Superoxide dismutase (SOD) is a scavenger of superoxide anion $\left(\mathrm{O}^{-}\right)$in the process of energy metabolism. $\mathrm{O}^{-}$is toxic, and SOD, therefore, functions to catalyze the reaction converting $\mathrm{O}_{2}^{-}$into $\mathrm{H}_{2} \mathrm{O}_{2}$, which is then metabolized into water through other reactions, thereby preventing tissue damage and toxicity. Therefore, an imbalance in $\mathrm{O}^{-}$and SOD concentrations results in toxicity. At present, the majority of studies have examined the association of manganese superoxide dismutase (Mn-SOD) and extracellular superoxide dismutase (Ec-SOD) gene polymorphisms with COPD.

$\mathrm{Mn}-\mathrm{SOD}$ is located in the region of $6 \mathrm{q} 25$. Mutations occurring in a locus within Mn-SOD gene exon region have been shown to lead to the production of differently expressed proteins and result in changes in intracellular signaling. A recent study by Guo et al demonstrated that the rs 2842958 (G5774A) polymorphism in the intron region of Mn-SOD gene is associated with airway hyperresponsiveness, as well as COPD. An allele at 5774 locus of Mn-SOD gene is a risk factor for COPD, and the ratio of $\mathrm{A}$ in patients with very severe COPD is significantly higher. ${ }^{17}$ At the same time, it is proved that the homozygote after Ec-SOD gene mutation in rs8192288 locus can cause the decline of lung function.

The Ec-SOD gene polymorphism can increase serum levels of SOD and therefore has a protective effect. It has been shown that the frequencies of $\mathrm{G}$ alleles, $\mathrm{CG}$ and $\mathrm{GG}$ genotypes at position 213 in healthy smokers are significantly higher than those in COPD patients, suggesting that Ec-SOD mutation at position 213 may prevent the occurrence and development of COPD through anti-inflammatory and antioxidative effects.

\section{COPD and the genetic polymorphism of the hydrolytic- antihydrolytic system Serine protease inhibitor I (SERPINAI)}

Serine protease inhibitor 1 (SERPINA1) gene is located on chromosome 14 and belongs to the serine protease inhibitor $\alpha 1$-antitrypsin family (AAT). The main function of SERPINA1 is to inactivate neutrophil elastase and prevent tissue damage. With respect to mutations, the most common mutation associated with disease is $\mathrm{Z}$ allele mutation, which reduces levels in the lungs and promotes emphysema. It has been reported that the polymorphisms rs8004738, rs17751769, rs709932, rs11832, rs1303, rs28929474 and rs17580 of SERPINA1 gene are associated with COPD. ${ }^{18}$ However, Chappell et al demonstrated that rs8004738 was associated with COPD. After confounding factors, such as age, were adjusted for, an association remained. ${ }^{19}$ Deng $\mathrm{X}$ et al have showed that SERPINA1 gene was correlated with COPD in Han Chinese after excluding confounding factor, which is similar to the Chappell. ${ }^{20}$ However, it is well known that racial differences exist between genetic risk and disease phenotype.

\section{Serine protease inhibitor 2 (SERPINE2)}

Serine protease inhibitor 2 (SERPINE2) is located in the 2q33.3-37.2 region and encodes an inhibitor of a serine protease with a molecular weight of 44,000 Da. SERPINE2 plays an important role in coagulation and fibrinolysis. The interaction between serine protease inhibitors and matrix metalloproteinases (MMPs) plays an important role in the development and progression of COPD. Demeo et al conducted a study involving 127 patients with severe COPD in the USA to explore the association of various phenotypes of COPD with 18 SNPs of the SERPINE2 gene. ${ }^{21}$ The authors found that only five loci were associated with the pathogenesis of COPD, with smoking playing an important role in gene expression. Zhu et al conducted a study on Bergen and Norwegian people to observe the relationships of the 25 loci of SERPINE2 gene in 1,910 persons from 635 families with COPD phenotypes. ${ }^{22}$ The authors conducted a case-control study including 973 COPD patients and 956 healthy controls, with the results showing that six SNPs were significantly associated with COPD phenotypes, and the differences in five SNPs were statistically significant $(P<0.05)$ between patient and healthy control groups. Chappell et al conducted a prospective study of 1,018 COPD patients and 911 healthy controls in six European countries and concluded that SERPINE gene polymorphisms were not associated with COPD. ${ }^{19}$ Additionally, a study in China by Wang, who conducted a case-control study on 409 COPD patients and 411 healthy controls, demonstrated that rs840088, rs1438831 and rs3795879 loci of the SERPINE2 gene were not associated with the pathogenesis of COPD. ${ }^{23}$ These findings may be accounted for by racial differences, as well as differences in the selection of control populations. Further investigation is required to examine the role of SERPINE2 gene polymorphisms in COPD susceptibility. 


\section{l-antichymotrypsin (SERPINA3)}

1-antichymotrypsin (SERPINA3) functions to inhibit cathepsin $\mathrm{G}$ and mast cells rennet. In the Swiss population, two loci polymorphisms of SERPINA3 are associated with decreased levels of l-antichymotrypsin. However, these have not been confirmed in the Japanese population. ${ }^{24,25}$

\section{Matrix metalloproteinases}

MMPs belong to the family of proteolytic enzymes, and their main role is to degrade the basement membrane and extracellular matrix following activation. Activated MMPs are inhibited by endogenous tissue inhibitor of metalloproteinases (TIMP), thereby preventing tissue fibrosis. In the protease family, MMP-1, MMP-9 and MMP-12 gene polymorphisms are thought to be closely associated with emphysema.

MMP-1 is located on the chromosome 11q22, with the -1607 position forming the core sequence in the transcription factor binding site. ${ }^{26}$ The wild type $(1 \mathrm{G} / 1 \mathrm{G})$ of the MMP-1 gene can reduce the expression level of the corresponding protease, and is a protective factor against decreased lung function. Sun et al conducted a case-control study on 59 patients with COPD and 109 healthy people in Northern China using PCR-RFLP technology and found that mutant homozygote of MMP-1 can reduce the incidence of $\mathrm{COPD}$ and is a protective factor. ${ }^{27}$ However, the meta-analysis of Jiang et al showed that MMP-1 rs1799750 1G >2G and MMP-3 rs3025058 5A $>6 \mathrm{~A}$ have little association with COPD ${ }^{28}$ MMP-9 is located on chromosome 20, and change in its promoter region-1562SNP can increase MMP activity, ${ }^{29,30}$ which has been confirmed in both Chinese and Japanese populations. European studies have shown that this locus is associated with the severity of COPD, and the frequency of gene mutations in grade 4 patients is significantly higher than those in grade 2 and 3 patients. A study by Ito et al demonstrated that polymorphisms in the MMP-9 allele are associated with progression of pulmonary emphysema in smokers with COPD. ${ }^{31}$ In the study of S Jiang, MMP-9 rs3918242 C > T was demonstrated to be associated with COPD. ${ }^{28}$ However, Demeo et al ${ }^{21}$ did not find any association between MMP-9 and COPD.

MMP-12 degrades elastin, and degraded elastin fragments recruit macrophages to release MMP-12, thereby forming a positive feedback loop. Hunninghake et al tested the association between SNPs encoding MMP12 gene and the indicator of lung function, $\mathrm{FEV}_{1}$, and demonstrated that the rs1276109 locus of the MMP12 gene may produce a protective effect on lung function in children with asthma and smokers, and can reduce the incidence of COPD in smoker. ${ }^{32}$ Joos et al studied the 5-year rate of decline in lung function in 590 smokers. ${ }^{33}$ The authors concluded that among the five observed SNPs, the haploid-type alleles from MMP1 G-1607GG and MMP12 Asn357Ser were also associated with the rate of decline of lung function $(P=0.0007)$. However, only the adjusted G-1607GG was associated with a fast rate of decline of lung function $(P=0.02)$.

\section{Disintegrin and metalloproteinase domain-containing protein 33 (ADAM33)}

Disintegrin and metalloproteinase domain-containing protein 33 (ADAM33) gene is located in the q23.13 region, and was first identified in 2002 as a related gene for airway hyperresponsiveness and bronchial asthma. ${ }^{34}$ ADAM33 is primarily expressed in smooth muscle cells and lung fibroblasts and is rarely expressed in other tissues. Dijkstra et al demonstrated that all members of the ADAM family are expressed in bronchial epithelium; however, expression patterns vary according to tissue. ${ }^{35}$ ADAM 33 is the only ADAM member that is predominantly and strongly expressed in bronchial epithelial basal cells.

In recent years, the role of ADAM33 gene polymorphisms in COPD has been a topic of intense research. A number of studies have demonstrated the relationship between different ethnic ADAM33 gene polymorphisms and COPD. In the study by Korytina et al, 319 patients and 514 healthy controls were selected. The results showed that 13491 and $12418 \mathrm{GG}$ haplotypes of ADAM33 gene significantly increase the incidence of COPD. ${ }^{36}$ Xiao et al demonstrated that seven loci (T2, T1, S1, S2, V4, Q-1, F+1) and four haplotypes $(\mathrm{H} 2, \mathrm{H} 5, \mathrm{H} 6, \mathrm{H} 9)$ of the ADAM33 gene are significantly associated with the pathogenesis of COPD in the Tibetan population of China. ${ }^{37}$ Wang et al conducted a case-control study on 312 COPD patients and 319 healthy volunteers and observed the association of eight SNPs of ADAM33 with COPD using PCR-RFLP. ${ }^{38}$ The results showed that the differences in the allele frequencies of T2G, T1G, S2C and Q-1G were statistically significant between the two groups, suggesting that ADAM33 is associated with the pathogenesis of COPD.

Studies have shown that ADAM33 gene polymorphisms are also significantly associated with decreased lung function. Sadeghnejad et al investigated the polymorphisms of 25 loci of ADAM33 genes in 880 Caucasians over 20 years and found that five SNPs (Q-1, S1, S2, V-1 and V4) are associated with the pathogenesis of COPD, and these five loci are associated with decrease in $\mathrm{FEV}_{1}, \mathrm{FEV}_{1} \%$ and $\mathrm{FEV}_{1} / \mathrm{FVC}^{39}$ 
Linkage disequilibrium and haplotype analysis suggested that the S1 locus has the strongest association with a decline in lung function. Qin et al discussed the association of ADAM33 gene polymorphism in Han population of Northern China with COPD and lung function, and found that ADAM33 gene polymorphisms are associated with COPD susceptibility, but not associated with disease severity. ${ }^{40}$

\section{COPD and polymorphisms in inflammation-related genes Vitamin $D$ binding protein}

Vitamin D binding protein (VDBP) is located in the 4q11-13 region and is a macrophage activation factor. However, VDBP also acts as a macrophage chemotactic factor and plays an important role in regulating inflammatory response and reducing the body's antioxidant capacity. Ito et al selected 103 COPD patients and 88 healthy smokers in Japan and used PCR-RFLP to observe the association between SNP in GC globulin and COPD. ${ }^{41}$ The results showed that the prevalence of the $\mathrm{GC}^{*} 1 \mathrm{~F}$ homozygote probability was significantly higher in COPD patients than that in healthy smokers $(P=0.01 ; \mathrm{OR}=2.3 ; 95 \% \mathrm{CI}=1.2-4.6)$, and COPD patients and $\mathrm{GC}^{*} 1 \mathrm{~F}$ alleles had a greater rate of $\mathrm{FEV}_{1}$ decline $(P=0.01)$, a higher low attenuation area percentage and a lower mean CT score. A recent Chinese study also found that GclF may be a risk factor for COPD and Gc2 is a protective factor for COPD. ${ }^{42}$

\section{Transforming growth factor- $\beta$ I (TGF- $\beta$ I)}

TGF- $\beta 1$ is an important factor involved in inflammation. Furthermore, it can regulate the induction of inflammatory factors involved in the development and progression of COPD. Celedon et al conducted a case-control study on smokers with COPD and found that rs1982073 in the exon region and rs2241712 and rs1800469 in the promoter region of TGF- $\beta 1$ gene are significantly associated with COPD. ${ }^{43}$ Liu et al selected 219 COPD patients and 148 healthy people from the Chinese Han population as the study subjects, and used amplification refractory mutation system-polymerase chain reaction to analyze $869 \mathrm{~T} / \mathrm{C}$ and $915 \mathrm{G} / \mathrm{C}$ polymorphisms of TGF- $\beta 1$ gene and performed genetic typing. ${ }^{44}$ The results showed that the frequency distribution of 869T/C polymorphism of TGF- $\beta 1$ gene in COPD group is significantly higher than that in control group $(P<0.05)$. $\mathrm{C}$ allele can increase the risk of COPD (OR $=1.131,95 \%$ $\mathrm{CI}=1.101-1.539$ ). The frequency distribution of the $915 \mathrm{G} / \mathrm{C}$ polymorphism in the TGF- $\beta 1$ gene has no significant difference between two groups $(P>0.05)$. Ogawa et al found that SNP of TC in 869 locus of TGF- $\beta 1$ gene is related to airway hyperresponsiveness, and is not related to the rapid decline in lung function. ${ }^{45}$

\section{Tumor necrosis factor}

Tumor necrosis factor- $\alpha$ (TNF- $\alpha)$ is an inflammatory factor secreted primarily by macrophages. TNF- $\alpha$ is located in the $6 \mathrm{p} 21.23$ region, and mainly increases the expression of inflammatory genes through the activation of nuclear factor-kB, and plays an important role in COPD as well as systemic inflammation. At present, the gene polymorphism of the -308 locus of TNF- $\alpha$ gene promoter has been studied; it can be divided into TNF- $\alpha 308 * 1$ and TNF- $\alpha 308 * 2$ according to different $\mathrm{G} / \mathrm{A}$ loci. The latter can induce high expression of TNF- $\alpha$, which is closely associated to the pathogenesis of COPD. Studies in Japan have shown that the TNF- $\alpha$ gene $-308 * 1 / 2$ locus SNP has a significant association with COPD. ${ }^{46}$ Huang et al studied 42 male patients with chronic bronchitis and 42 healthy controls matched by gender, age and smoking index and randomly selected and studied nine students. ${ }^{47}$ The results showed that the TNF2 allele was overexpressed in the COPD group; the frequency of TNF- $\alpha$ allele was $5.1 \%$ in the students, $2.4 \%$ in the control group and $19 \%$ in the bronchitis group $0(P<0.01)$. The TNF2 allele may contribute to the development of chronic bronchitis $(\mathrm{OR}=11.1$, $95 \% \mathrm{CI}=2.89-42.57$ ). Louis et al observed 62 cases of individuals, and the results confirmed that TNF- $\alpha 308 * 2$ allele frequency in patients with COPD was significantly higher than that in the control group. ${ }^{48}$ Furthermore, a Chinese study also found the same results. ${ }^{49}$ However, this association is not apparent in Italian and Caucasian populations. ${ }^{50,51}$ Such a result may be due to genetic differences between races. Keatings conducted a cross-sectional study on 106 patients with COPD and 99 healthy controls and carried out a 2-year follow-up to observe whether the frequency of the A allele was increased in the COPD group. ${ }^{52}$ The authors found that AA homozygotes had a decreased reversible airway obstruction and a higher mortality rate, suggesting that homozygous allele $\mathrm{A}$ is a predictor of worse prognosis in COPD. Patuzzo concluded that in the Caucasian individuals, the TNF gene and its polymorphism do not increase the risk of COPD and bronchiectasis. ${ }^{53}$ In addition to TNF- $\alpha-308$ locus, gene polymorphisms of loci, such as TNF- $\alpha+489 \mathrm{G} / \mathrm{A}, \mathrm{TNF}-\alpha-376 \mathrm{G} / \mathrm{A}$ and TNF- $\alpha-238 \mathrm{G} / \mathrm{A}$, have also been identified. A recent study has shown that TNF- $\alpha+489 \mathrm{G} / \mathrm{A}$ gene polymorphism is associated with susceptibility to COPD in Caucasians. ${ }^{54}$ 


\section{Others}

\section{$\beta 2$-adrenergic receptor}

$\beta 2$-adrenergic receptors (ADRB2) are mainly distributed in the alveolar wall, endothelium, pulmonary arterial smooth muscle, tracheal smooth muscle and bronchial epithelium. ADRB2 belong to G protein-coupled receptors, with a seven-transmembrane structure, regulating airway contraction. Thomsen et al found that the mutation in locus 164 of ADRB2 gene can increase the risk of occurrence of COPD in Danish people. ${ }^{55}$

\section{Other pathogenesis of COPD}

COPD is a disease characterized by genetic and phenotypic heterogeneity. Although association studies have identified that multiple genomic regions are associated with COPD, genetic variation only partially explains susceptibility to lung diseases, and the following will briefly introduce the association between epigenetics and COPD.

\section{Epigenetics and COPD}

Epigenetics refers to the process of influencing gene expression through other genetic mechanisms without affecting DNA sequences. Currently identified epigenetic mechanisms include DNA methylation, histone methylation and acetylation, as well as noncoding RNAs such as microRNA. Barreiro and Gea elaborated on the effects of epigenetic mechanisms on muscle development, which resulted in COPD. ${ }^{56}$ DNA epigenetic modifications include DNA methylation, covalent histone modification, noncovalent mechanisms and noncoding RNAs such as microRNAs. DNA methylation usually occurs at cytosine and guanosine nucleotide $(\mathrm{CpG})$ islands, mainly by adding the methyl group to 5 '-terminal of the cytosine. DNA methylation can alter the corresponding chromatin structure, thereby aggregating chromatin into clusters, resulting in a loss of transcription activity. In skeletal muscle, it mainly reduces muscle tissue by inhibiting the differentiation of muscle satellite cells and thus increases the incidence of COPD. The study of Morrow et al on DNA methylation in COPD patients showed that the loci of differential methylation were located in CHRM1, GLT1D1 and C10 or f11, and if they were ranked by GWAS $P$-value, the top loci included FRMD4A, THSD4 and C10 or f1 $1 .{ }^{57}$ In the process of muscle development, microRNAs (miRNAs) play an important role, and many miRNAs are tissue-specific, and miR-1, miR-133 and miR-206 are abundant in skeletal muscle. MiR-133 promotes muscle differentiation through targeting HDAC4, and miR-133 inhibits serum response factor to stimulate the myoblast proliferation and thus inhibit myotubule formation; miR-206 promotes myotubule formation through p180 subunit targeting DNA polymerase $\alpha$. A report showed that miR-206 and miR-486 are beneficial for differentiation of myoblasts, and inhibiting their expressions may activate Pax7 and thus delay differentiation. The study of Wang et al showed that loss of miR-29 induces transdifferentiation of myoblasts into myofibroblasts, whereas in Duchenne myodystrophy model, miR-29 expression can reduce the muscles with malnutrition. ${ }^{58}$ The above epigenetic changes may affect the main factors of muscle dysfunction and muscle mass loss in patients with COPD. The study of Lewis et al showed that in the lateral femoral muscle of patients with severe COPD, miR-1 expression is significantly decreased and HDAC4 protein level is significantly increased. ${ }^{59} \mathrm{~A}$ case-control study of Donaldson et al demonstrated that the levels of several muscle-specific miRNAs such as miRNA-1, miR-499, miR-181, miR-133 and miR-206 are significantly increased in the plasma of patients with severe COPD, and the differences are significant compared with the control group, but it is proved that miRNA expression cannot predict the muscle fiber area or composition in COPD patients in the same study. ${ }^{60}$ An important study of UK BiLEVE found that KANSL1 gene, coding a subunit of a histone acetyltransferase (HAT) complex, which is vital for epigenetic gene regulation, was related with extremes of FEV. ${ }^{3}$

\section{Apoptosis and COPD}

In addition, the abnormal apoptosis plays an important role in the pathogenesis of emphysema. B cell CLL/lymphoma 2 (Bcl-2) family proteins are a necessary key regulatory factor of apoptosis. The study of Zeng et al has shown that decreased Bcl-2 expression and Bcl-2 promoter hypermethylation can cause lung cell apoptosis and decreased lung function. 5-aza-20-deoxycytidine (AZA) increases Bcl-2 expression and $\mathrm{Bcl}-2$ promoter demethylation. AZA can also reduce lung cell apoptosis and functional failure induced by cigarette smoke extract. ${ }^{61}$

In summary, the pathogenesis of COPD involves multiple factors. The specific etiology of COPD cannot be determined according to current studies. Therefore, the determination of pathogenic factors for COPD is still in early stages. As a result, further studies are required in order to elucidate the pathways involved in the susceptibility of COPD.

\section{Acknowledgments}

This work was supported by Beijing Nova Program (Z171100001117012), National Natural Science Foundation 
of China (grant no 81402471), National Major Scientific and Technological Special Project for "Significant New Drugs Development" (grant no 2015ZX09J15102-003) and Basic Research Program of General Hospital of Chinese People's Armed Police Forces (grant no WZ2014026).

\section{Disclosure}

The authors report no conflicts of interest in this work.

\section{References}

1. Boueiz A, Lutz SM, Cho MH, et al. Genome-wide association study of the genetic determinants of emphysema distribution. Am J Respir Crit Care Med. 2017;195(6):757-771.

2. Manichaikul A, Hoffman EA, Smolonska J, et al. Genome-wide study of percent emphysema on computed tomography in the general population. The Multi-Ethnic Study of Atherosclerosis Lung/SNP Health Association Resource Study. Am J Respir Crit Care Med. 2014; 189(4):408-418.

3. Wain LV, Shrine N, Miller S, et al. Novel insights into the genetics of smoking behaviour, lung function, and chronic obstructive pulmonary disease (UK BiLEVE): a genetic association study in UK Biobank. Lancet Respir Med. 2015;3(10):769-781.

4. Wain LV, Shrine N, Artigas MS, et al. Genome-wide association analyses for lung function and chronic obstructive pulmonary disease identify new loci and potential druggable targets. Nat Genet. 2017;49(3): 416-425.

5. Udomsinprasert R, Pongjaroenkit S, Wongsantichon J, et al. Identification, characterization and structure of a new Delta class glutathione transferase isoenzyme. Biochem J. 2005;388(Pt 3):763-771.

6. Harrison DJ, Cantlay AM, Rae F, Lamb D, Smith CA. Frequency of glutathione S-transferase M1 deletion in smokers with emphysema and lung cancer. Hum Exp Toxicol. 1997;16(7):356-360.

7. Shukla RK, Kant S, Bhattacharya S, Mittal B. Association of genetic polymorphism of GSTT1, GSTM1 and GSTM3 in COPD patients in a north Indian population. COPD. 2011;8(3):167-172.

8. He JQ, Ruan J, Connett JE, et al. Antioxidant gene polymorphisms and susceptibility to a rapid decline in lung function in smokers. $\mathrm{Am} \mathrm{J}$ Respir Crit Care Med. 2002;166(3):323-328.

9. Yang L, Li X, Tong X, Fan H. Association between glutathione S-transferase P1 Ile (105) Val gene polymorphism and chronic obstructive pulmonary disease: a meta-analysis based on seventeen case-control studies. Meta Gene. 2015;6:59-64.

10. Srivastava D. Microsomal epoxide hydrolase gene polymorphisms and susceptibility to prostate cancer: a systematic review. Indian J Cancer. 2016;53(2):213-215.

11. Hassett C, Lin J, Carty CL, Laurenzana EM, Omiecinski CJ. Human hepatic microsomal epoxide hydrolase: comparative analysis of polymorphic expression. Arch Biochem Biophys. 1997;337(2): 275-283.

12. Sandford AJ, Chagani T, Weir TD, et al. Susceptibility genes for rapid decline of lung function in the lung health study. Am J Respir Crit Care Med. 2001;163(2):469-473.

13. Yim JJ, Park GY, Lee CT, et al. Genetic susceptibility to chronic obstructive pulmonary disease in Koreans: combined analysis of polymorphic genotypes for microsomal epoxide hydrolase and glutathione S-transferase M1 and T1. Thorax. 2000;55(2):121-125.

14. An L, Xia H, Zhou P, Hua L. Exploration of association between EPHX1 and chronic obstructive pulmonary disease on the basis of combined data mining. Genet Mol Res. 2016;15(2).

15. Wei J, Zhao H, Li J. [The anti-inflammatory effects of heme oxygenase-1 on emphysema model]. Zhonghua Jie He He Hu Xi Za Zhi. 2015;38(5):379-383. Chinese.
16. Yamada N, Yamaya M, Okinaga S, et al. Microsatellite polymorphism in the heme oxygenase-1 gene promoter is associated with susceptibility to emphysema. Am J Hum Genet. 2000;66(1):187-195.

17. Guo F, Kuang JL. [Superoxide dismutase gene polymorphisms and functional activity in chronic obstructive pulmonary disease]. Zhonghua Jie He He Hu Xi Za Zhi. 2011;34(6):424-428. Chinese.

18. Fujimoto K, Ikeda S, Arai T, et al. Polymorphism of SERPINE2 gene is associated with pulmonary emphysema in consecutive autopsy cases. BMC Med Genet. 2010;11:159.

19. Chappell S, Daly L, Morgan K, et al. The SERPINE2 gene and chronic obstructive pulmonary disease. Am J Hum Genet. 2006;79(1):184-186; author reply $186-187$

20. Deng X, Yuan CH, Chang D. Interactions between single nucleotide polymorphism of SERPINA1 gene and smoking in association with COPD: a case-control study. Int J Chron Obstruct Pulmon Dis. 2017;12: 259-265.

21. Demeo DL, Mariani TJ, Lange C, et al. The SERPINE2 gene is associated with chronic obstructive pulmonary disease. Am J Hum Genet. 2006;78(2):253-264.

22. Zhu G, Warren L, Aponte, et al. The SERPINE2 gene is associated with chronic obstructive pulmonary disease in two large populations. Am J Respir Crit Care Med. 2007;176(2):167-173.

23. Wang AH. Study on Association of SERPINE2 Gene Polymorphism with Chronic Obstructive Pulmonary Disease [Doctor Degree thesis]. China: Shandong University; 2012.

24. Poller W, Meisen C, Olek K. DNA polymorphisms of the alpha 1-antitrypsin gene region in patients with chronic obstructive pulmonary disease. Eur J Clin Invest. 1990;20(1):1-7.

25. Poller W, Faber JP, Weidinger S, et al. A leucine-to-proline substitution causes a defective alpha 1-antichymotrypsin allele associated with familial obstructive lung disease. Genomics. 1993;17(3):740-743.

26. An HY, Ling M. Research progress of susceptibility gene in chronic obstructive pulmonary disease. Clin Med. 2012;32:105-107.

27. Sun PZ, Chen J, Chen RY, Jin JJ, Li YJ. The relevance of matrix metalloproteinase-1 gene polymorphism with chronic obstructive pulmonary disease susceptibility in Han nationality of northern China. Chin J Respir Crit Care Med. 2005;4:342-344.

28. Jiang S, Yang ZH, Chen YY, et al. MMP-9 genetic polymorphism may confer susceptibility to COPD. Genet Mol Res. 2016;15(2).

29. Minematsu N, Nakamura H, Tateno H, Nakajima T, Yamaguchi K. Genetic polymorphism in matrix metalloproteinase-9 and pulmonary emphysema. Biochem Biophys Res Commun. 2001;289(1):116-119.

30. Zhou M, Huang SG, Wan HY, Li B, Deng WW, Li M. Genetic polymorphism in matrix metalloproteinase- 9 and the susceptibility to chronic obstructive pulmonary disease in Han population of south China. Chin Med J. 2004;117(10):1481-1484.

31. Ito I, Nagai S, Handa T, et al. Matrix metalloproteinase-9 promoter polymorphism associated with upper lung dominant emphysema. Am J Respir Crit Care Med. 2005;172(11):1378-1382.

32. Hunninghake GM, Cho MH, Tesfaigzi Y, et al. MMP12, lung function, and COPD in high-risk populations. N Engl J Med. 2009;361(27): 2599-2608.

33. Joos L, He JQ, Shepherdson MB, et al. The role of matrix metalloproteinase polymorphisms in the rate of decline in lung function. Hum Mol Genet. 2002;11:569-576.

34. Van Eerdewegh P, Little RD, Dupuis J, et al. Association of the ADAM33 gene with asthma and bronchial hyperresponsiveness. Nature. 2002; 418(6896):426-430.

35. Dijkstra A, Postma DS, Noordhoek JA, et al. Expression of ADAMs ("a disintegrin and metalloprotease") in the human lung. Virchows Arch. 2009;454(4):441-449.

36. Korytina GF, Tselousova OS, Akhmadishina LZ, Victorova EV, Zagidullin ShZ, Victorova TV. [Association of the MMP3, MMP9, ADAM33 and TIMP3 genes polymorphic markers with development and progression of chronic obstructive pulmonary disease]. Mol Biol (Mosk). 2012;46(3):487-499. 
37. Xiao J, Han J, Wang X, et al. Association of ADAM33 gene with susceptibility to COPD in Tibetan population of China. Mol Biol Rep. 2011;38(8):4941-4945.

38. Wang X, Li L, Xiao J, et al. Association of ADAM33 gene polymorphisms with COPD in a northeastern Chinese population. BMC Med Genet. 2009;10:132.

39. Sadeghnejad A, Ohar JA, Zheng SL, et al. Adam 33 polymorphisms are associated with COPD and lung function in long-term tobacco smokers. Respir Res. 2009;10:21.

40. Qin RJ, Wang H, Guo CC. Association between single nucleotide polymorphisms and haplotypes in ADAM33 gene and chronic obstructive pulmonary disease. Int J Respir. 2012;32:182-187.

41. Ito I, Nagai S, Hoshino Y, et al. Risk and severity of COPD is associated with the group-specific component of serum globulin $1 \mathrm{~F}$ allele. Chest. 2004;125(1):63-70.

42. Lu M, Yang B, Cai YY. [The relationship between vitamin D binding protein gene polymorphism and chronic obstructive pulmonary disease]. Zhonghua Nei Ke Za Zhi. 2004;43(2):117-120. Chinese.

43. Celedon JC, Lange C, Raby BA, et al. The transforming growth factorbeta1 (TGFB1) gene is associated with chronic obstructive pulmonary disease (COPD). Hum Mol Genet. 2004;13(15):1649-1656.

44. Liu DS, Li XO, Ying BW, et al. Effects of single nucleotide polymorphisms $869 \mathrm{~T} / \mathrm{C}$ and $915 \mathrm{G} / \mathrm{C}$ in the exon 1 locus of transforming growth factor-betal gene on chronic obstructive pulmonary disease susceptibility in Chinese. Chin Med J. 2010;123(4):390-394.

45. Ogawa E, Ruan J, Connett JE, Anthonisen NR, Paré PD, Sandford AJ. Transforming growth factor-beta1 polymorphisms, airway responsiveness and lung function decline in smokers. Respir Med. 2007;101(5):938-943.

46. Sakao S, Tatsumi K, Igari H, Shino Y, Shirasawa H, Kuriyama T. Association of tumor necrosis factor alpha gene promoter polymorphism with the presence of chronic obstructive pulmonary disease. Am J Respir Crit Care Med. 2001;163(2):420-422.

47. Huang SL, Su CH, Chang SC. Tumor necrosis factor-alpha gene polymorphism in chronic bronchitis. Am J Respir Crit Care Med. 1997; 156(5):1436-1439.

48. Louis E, Franchimont D, Piron A, et al. Tumour necrosis factor (TNF) gene polymorphism influences TNF-alpha production in lipopolysaccharide (LPS)-stimulated whole blood cell culture in healthy humans. Clin Exp Immunol. 1998;113(3):401-406.
49. Ma ZM, Zhang ZX, Han ZM. A study on the relationship between tumor necrosis factor $\alpha$ gene promoter polymorphism and the expressive levels of TNF- $\alpha$ protein. J Clin Intern Med. 2005:22(4):230-232.

50. Ferrarotti I, Zorzetto M, Beccaria M, et al. Tumour necrosis factor family genes in a phenotype of COPD associated with emphysema. Eur Respir J. 2003;21(3):444-449.

51. Teramoto S, Ishii T. No association of tumor necrosis factor-alpha gene polymorphism and copd in Caucasian smokers and Japanese smokers. Chest. 2001;119(1):315-316.

52. Keatings VM, Cave SJ, Henry MJ, et al. A polymorphism in the tumor necrosis factor-alpha gene promoter region may predispose to a poor prognosis in COPD. Chest. 2000;118(4):971-975.

53. Patuzzo C, Gile LS, Zorzetto M, et al. Tumor necrosis factor gene complex in COPD and disseminated bronchiectasis. Chest. 2000; 117(5):1353-1358.

54. Kucukaycan M, Van Krugten M, Pennings HJ, et al. Tumor necrosis factor-alpha $+489 \mathrm{G} /$ A gene polymorphism is associated with chronic obstructive pulmonary disease. Respir Res. 2002;3:29.

55. Thomsen M, Nordestgaard BG, Sethi AA, Tybjaerg-Hansen A, Dahl M. $\beta 2$-adrenergic receptor polymorphisms, asthma and COPD: two large population-based studies. Eur Respir J. 2012;39(3):558-566.

56. Barreiro E, Gea J. Epigenetics and muscle dysfunction in chronic obstructive pulmonary disease. Transl Res. 2015;165(1):61-73.

57. Morrow JD, Cho MH, Hersh CP, et al. DNA methylation profiling in human lung tissue identifies genes associated with COPD. Epigenetics. 2016:1-10. Epub August 26, 2016.

58. Wang L, Zhou L, Jiang P, et al. Loss of miR-29 in myoblasts contributes to dystrophic muscle pathogenesis. Mol Ther. 2012;20(6):1222-1233.

59. Lewis A, Riddoch-Contreras J, Natanek SA, et al. Downregulation of the serum response factor/miR-1 axis in the quadriceps of patients with COPD. Thorax. 2012;67(1):26-34.

60. Donaldson A, Natanek SA, Lewis A, et al. Increased skeletal musclespecific microRNA in the blood of patients with COPD. Thorax. 2013; 68(12):1140-1149.

61. Zeng H, Shi Z, Kong X, et al. Involvement of B-cell CLL/lymphoma 2 promoter methylation in cigarette smoke extract-induced emphysema. Exp Biol Med (Maywood). 2016;241(8):808-816.
International Journal of COPD

\section{Publish your work in this journal}

The International Journal of COPD is an international, peer-reviewed journal of therapeutics and pharmacology focusing on concise rapid reporting of clinical studies and reviews in COPD. Special focus is given to the pathophysiological processes underlying the disease, intervention programs, patient focused education, and self management protocols.

\section{Dovepress}

This journal is indexed on PubMed Central, MedLine and CAS. The manuscript management system is completely online and includes a very quick and fair peer-review system, which is all easy to use. Visit http://www.dovepress.com/testimonials.php to read real quotes from published authors. 